\title{
A cross-sectional study of factors determining empathy levels among un- dergraduate medical students of a medical college in Northern Telangana.
}

\author{
R. Shiv Kumar ${ }^{1}$, Puli SK ${ }^{2}$, P.Kishan ${ }^{2}$, Sanjay ND³, Pusukuri Sphurthi ${ }^{4}$, Ayesha Sultana ${ }^{4}$, Kashif Momin ${ }^{5}$
}

1. Assistant Professor, Department Of Psychiatry, Prathima Institute Of Medical Sciences, Nagunoor, Karimnagar, Telangana.

2. Professor \& Head Department of Psychiatry, Prathima Institute Of Medical Sciences, Nagunoor, Karimnagar

3. Resident, Prathima Institute of Medical Sciences, Nagunoor, Karimnagar,

Submission : 10-9-2020

4. Post Graduate, Prathima Institute of Medical Sciences, Nagunoor, Karimnagar,

Review : 15-10-2020

5. Associate Professor, Department Of SPM, PIMS. Prathima Institute of Medical Sciences, Nagunoor, Karimnagar

Acceptance 19-10-2020

CORRESPONDING AUTHOR: Dr. Sai Krishna Puli, Professor, Department Of Psychiatry. Prathima Institute Of Medical Sciences, Nagunoor, Karimnagar, Telangana, PIN -505001 Email:kannap103@gmail.comＣontact: 9849529800

DOI: 10.47799/pimr.0803.11

(C) 2020-21 Prathima Institue of Medical Sciences

\section{Abstract}

Background: The development of an ideal doctor-patient relationship requires empathy. Empathetic conversation aids in the formation of an open and trusting equation between doctor and patient. Furthermore, this leads to accurate diagnoses and more compliance to the advised treatment. In this manner, empathy helps in overall recovery of the patient and improves global functioning and generalised well-being.

This study aims to make note of the fluctuation in empathy levels during medical education. Studies done in various countries have found factors such as curriculum, clinical rotations timing and gender to progressively influences empathy levels in students throughout their medical training.

The recent trend of violence against healthcare professionals in India calls for an urgent action into the gap between doctors and patients communication. Empathy towards patients and attendants will reduce such untoward events. In this current context, we should improve empathy levels among the training doctors. As a first step, we should assess various factors affecting empathy among health care professionals.

Method: This cross sectional study was done among undergraduates of a rural medical college in Northern Telangana during the time period of October to December 2019. Their empathy levels were assessed using Jefferson's Scale for Empathy- Student version (JSE-S).

Result: Of the 470 students surveyed, 227 were males and 243 females. Female students were having higher empathy among first year and second years $(p<0.001)$. Empathy levels seem to decline from first year to second year following which the mean empathy remains similar throughout the remaining years in students of both sexes. There is no significant relation between mean empathy scores and choice of future speciality ( $p>0.05)$.

Conclusion: Female undergraduate students are found to be more empathetic than their male counterparts. A fall in empathy scores from the first to second year of MBBS is seen, which is when students enter their clinical rotations. Targeted intervention at this time may go a long way in the creation of a new generation of more empathetic physicians. Hence, there is a need for evaluation of teaching and learning techniques in medical education.

Further, there is a call for more research into the determinants of decline in empathy amongst medical professionals.

Keywords: Medical undergraduates, Empathy, Jefferson Empathy Scale

Introduction

Empathy was derived from word "empatheia", which means affection or passion with a quality of suffering. ${ }^{[1]}$ Empathy is the ability to relate to what another person is feeling or experiencing. It involves cognitive and affective domains of human learning. It includes sensitivity to patients need and the behavioural capability to convey what is necessary and effectively communicate with patients. ${ }^{[2]}$

Empathetic communication forms a relationship of trust and openness between a health-care provider and patient, aiding in more accurate diagnoses and compliance to treatment. It is therefore a crucial factor in the treatment outcome and overall quality of healthcare. ${ }^{[3]}$

Mercer and Reynolds have stated that empathy of healthcare workers is a complex, multidimensional entity including: understanding the patient, reflecting your understanding, checking whether you understood the patient right and acting upon that understanding in a therapeutic way. ${ }^{[4]}$

William Osler said, "it is as important to know what kind of a man has the disease as to know what kind of a disease has the man", thus aptly summing up the concept of empathy. ${ }^{[5]}$ Empathetic doctors appear to experience greater job satisfaction and psychological well-being and have been found to take clinical decisions in a better way and are effective transformational leaders. ${ }^{[6]}$

Hojat et al. reported that medical professionals with more empathy had more clinical competence than academic competence. They also found that empathetic doctors are 
more successful in clinical practice, have better patient recovery and lesser medico-legal issues. ${ }^{[7]}$

Some determinants of empathy found in health professionals are their choice of speciality ${ }^{[7]}$ and gender ${ }^{[8]}$. Life experience and personal maturation are found to be facilitators for empathetic behaviour development. ${ }^{[9]}$

Studies by Newton and Chen had found significant fall in empathy levels of students when they entered into their clinical training years . ${ }^{[10-12]}$ Study by Kataoka HU in Japan had found a rise in empathy when students moved to clinical rotation ${ }^{[13,14]}$. Differences could be due to changes in curriculum content and timings of clinical rotations. In Indian medical schools, clinical rotation and exposure to patients start from second year only. Studies by various researchers across the globe had found that medical students who showed an inclination to pursue people-oriented specializations such as Psychiatry, Family Medicine, Paediatrics and Internal Medicine showed higher empathetic scores than those students who were interested in pursuing technology-oriented specialities such as surgery, radiology, and anaesthesiology. ${ }^{[12,15]}$

Newton et al reported a significant (2.25-fold decrease) decline of empathy across medical years of education in those who choose non-people oriented subjects for their future carrer specialization. ${ }^{[10]}$ In contrast, Rahimi-Madiseh $\mathrm{M}$ et al found no significant difference in empathy levels across various years of medical training. ${ }^{[16]}$

In his studies, Paula Neures et. al had found a decline in empathy in dentistry, veterinary, pharmacy and nursing students. ${ }^{[17]}$

Studies have suggested that females, because of their maternal instincts, have greater perceptions of emotions and are more receptive than males. As a result they have better understanding and higher empathy. Females have consistently scored significantly higher on empathy scales than male students among medical students $(p<0.01){ }^{[7,16,18]}$

This could be explained by a correlation found by Rueckert and Naybar between the activation of the right cerebral hemisphere and empathy among women. $\left.{ }^{[19}\right]$ Parental investment theory was also considered as an explanation to higher empathy levels among women. According to this theory, mothers are expected to develop a stronger sense of caring and to be more skilled in understanding their offsprings' emotional needs in order to ensure their survival. Studies conclude that women have greater emotional receptivity and are likely to have more humanistic attitudes, greater social sensitivity and greater care. The neurobiology of women's brains states that they have more active, busy mirror neurons. That is, females mimic or mirror the emotional response that we expect to feel in a given condition. ${ }^{[20]}$ Neurological imaging (FMRI) shows the level of ACC and Al activity is greater in women when they see others suffering. Specifically, in human brain inferior frontal cortex mediates emotional empathy, ventro-medial prefrontal cortex mediates cognitive empathy. ${ }^{[21]}$ On the other hand, men would tend to adopt attitudes of "justice, independence, and control". ${ }^{[22]}$

Need for the study: Studies across the globe had noticed varying levels of empathy across years in medical students. Indian system of medical education is different when compared to the western countries. We should try to understand and measure the empathy score levels, across various dimensions like sex, specialities (technology oriented vis-à-vis people oriented) they are planning to choose in future, so that corrective measures if required can be addressed from beginning only. With this need, this study was conducted.

\section{Material and method:}

This survey was conducted in Prathima Institute of Medical Science, Karimnagar, Telangana between Octobers - December 2019. Prior sanction of the Institutional Ethical Committee was obtained [IEC/PIMS/2019-002-23092019]. Prior permission of the principal author of JSE-S was obtained for utilizing and analysing the data. Undergraduate medical students of four years and interns were approached in their respective lecture halls and briefly explained the nature of the study. Written consent was obtained. Demographic particulars such as age, gender, year of study and choice of speciality were collected from the students. The printed questionnaires of the Jefferson's scale for physician empathy (JSE-S) were provided to be filled out and asked to submit in the class itself.

To assess the effect of choice of specialization on empathy, we had grouped students according to Jefferson's scale into:

A) People-oriented specialities (family medicine, community medicine, general internal medicine, paediatrics, psychiatry, obstetrics and gynaecology)

B) Technology-oriented specialities (anaesthesiology, pathology, radiology, surgery and surgical specialities)

C) Other specialities (medical subspecialties, dermatology, emergency medicine, undecided etc.) ${ }^{[23]}$

Students unwilling to participate or to give consent were excluded. Those who were absent at the time of the survey were not contacted.

This college had more female students when compared to male in each year. The batch of first year MBBS had just completed 3 months following admission and second-year had finished 2 months of clinical rotation. The third and final years were three months away from their examinations. Interns were to finish training in 3 months.

Scale/tool used: Jefferson's scale for physician empathyStudent Version (JSE-S) was used. It is specially designed to study empathy among medical students. ${ }^{[7]}$ It is a 20 -item psychometrically validated instrument. Ten of the items are negative statements and marked in the reverse order The respondent can indicate their level of agreement to each statement on a seven-point Likert scale, thus possible score 
ranges from 20 to 140 . The level of empathy is directly proportional to the final added score.. ${ }^{[23]}$ The English version of the scale was used in the present study.

Statistical Analysis: The data was tabulated in a Microsoft Excel sheet, analysed by EPI INFO (Epidemiological Information) -6 software.

Descriptive statistics are presented as mean of empathy, standard deviations with $95 \%$ confidence intervals for gender, year and choice of speciality.

In inferential statistics, the student t-test was used for gender. For the year of education and choice of specialisation, analysis of variance (ANOVA) was calculated for comparisons. P-value of less than 0.05 was considered to indicate statistical significance.

\section{RESULTS:}

Of 750 students of the college, 470 (243 Females and 227 males) participated in the study. Current study has participation rate of $62.7 \%$. There were an equal number of male and female students in the first and third year. Among second year participants, females exceeded males, comprising $58 \%$. In fourth year, females were $53 \%$, whereas in internship $56.5 \%$ students were male. The year-wise difference in male and female students is not statistically significant $(p=0.43)$.

The possible range of JSE-S Empathy scores is $20-140$. The mean empathy score of all students was 101.4 (Range 49 135) and median $=101$, with a standard deviation of 15.14 (Table 1). The 20-item empathy scale was observed to have good internal consistency in this study group $(a=0.742)$.

Table 1: Descriptive Statistics of the JSE-S scores of medical students

\begin{tabular}{|llll|}
\hline Descriptive Statistics & $\begin{array}{l}\text { Male Medical Students } \\
(\mathrm{n}=227)\end{array}$ & $\begin{array}{l}\text { Male Medical Students } \\
(\mathrm{n}=227)\end{array}$ & $\begin{array}{l}\text { Total Medical Students } \\
(\mathrm{N}=470)\end{array}$ \\
\hline Mean & 98.4 & 104.3 & 101.4 \\
Standard Deviation & 14.7 & 15.1 & 15.14 \\
Median (50th percentile) & 98 & 104 & 101 \\
25th Percentile & 90 & 95 & 91 \\
75th Percentile & 109 & 115 & 112 \\
Possible range1 & $20-140$ & $20-140$ & $20-140$ \\
Actual range2 & $51-134$ & $49-135$ & $49-135$ \\
\hline
\end{tabular}

1 The minimum and maximum possible scores.

2 The lowest and highest scores obtained in the study.

Genderwise : Female medical students had significantly higher scores of empathy than male students (Table 2). In this study particularly higher empathy in female students than in male students was present only in the first and second year students (Figure 1). From third year to internship, there was no statistically significant difference between male and female empathy scores (See Figure 1).

Table 2: Association between characteristics of medical students and JSE-S scores.

\begin{tabular}{|lllll|}
\hline Characteristics & Number & $\begin{array}{l}\text { Mean }( \pm \text { Standard } \\
\text { Deviation) }\end{array}$ & $\begin{array}{l}\text { 95\% Confidence } \\
\text { Interval }\end{array}$ & Significance* \\
\hline $\begin{array}{l}\text { Gender } \\
\text { Male }\end{array}$ & 227 & $98.4( \pm 14.7)$ & $96.4-100.3$ & $\mathrm{t}(\mathrm{df}=468)=-4.3$ \\
$\quad$ Female & 243 & $104.3( \pm 15.1)$ & $102.4-106.2$ & $\mathrm{p}<0.001$ \\
\hline Year & & & & \\
First & 100 & $104.1( \pm 15.50)$ & $101.1-107.2$ & $\mathrm{~F}(4,465)=1.4$ \\
Second & 108 & $102.2( \pm 14.6)$ & $99.4-104.9$ & \\
Third & 100 & $100.5( \pm 15.4)$ & $97.5-103.6$ & \\
Fourth & 100 & $100.3( \pm 15.1)$ & $97.3-103.3$ & \\
Internship & 62 & $99.1( \pm 14.9)$ & $95.3-102.9$ & \\
\hline
\end{tabular}




\begin{tabular}{|lllll|}
\hline Choice of Speciality & $160(\mathrm{FH}-86)$ & $101.2( \pm 15.5)$ & $98.8-103.7$ & $\mathrm{~F}(2,467)=0.4$ \\
$\begin{array}{l}\text { People Oriented } \\
\text { Speciality }\end{array}$ & $158(\mathrm{F \# -73)}$ & $100.8( \pm 15.1)$ & $98.4-103.2$ & $\mathrm{p}=0.67$ \\
Technology oriented & & $( \pm 14.9)$ & $99.9-104.7$ & \\
Speciality & $152(\mathrm{F \# -84)}$ & & \\
Other Specialities & & & & \\
\hline
\end{tabular}

* Independent $t$ test for gender and one-way ANOVA for year and choice of speciality used

\# F = Female students.

Year wise: Overall, there is no significant difference in mean empathy scores in medical students year wise (Table 2 ).

When year wise analysis is done in male and female students separately, it reveals that there is decline in empathy from first year to second year and then the mean empathy remains similar in rest of years both in male and female students (See Table 3 and figure 1). This may be a result of a shift from virtual, imaginative study in first year to real-time experiences via community exposure in clinicals from the second year onwards.

There was a statistically significant difference of empathy yearwise in female students as determined by one-way ANOVA, but no such difference was found in male students (Table 3 ).

Post Hoc tests using Bonferroni showed significantly higher mean empathy scores in first-year female students when compared to third-year female students. In other year female students' empathy, no statistically significant difference was noted. (Table 3 ).
Choice of Speciality: In the present- study, no significant association between choice of speciality and empathy levels was found.

Out of 160 students who showed interest in people-oriented specialities, 86(54\%) were females. Of 152 who hadn't chosen yet/chose other specialities, 84(55\%) were female students. Out of 158 students who chose technology-oriented specialities, $73(46 \%)$ were females (Table 2 ). A chi-square test of independence showed that there was no significant association between gender and preference of speciality.

At the same time, mean values of empathy scores did not differ significantly based on choice of speciality of students overall (See Table 2), and in male and in female students separately. Moreover, there was no statistically significant difference in empathy among groups of choices of speciality across the year of education ( $p>0.05)$.

Figure 1: Graph showing the difference of Empathy between male and female students in each year.

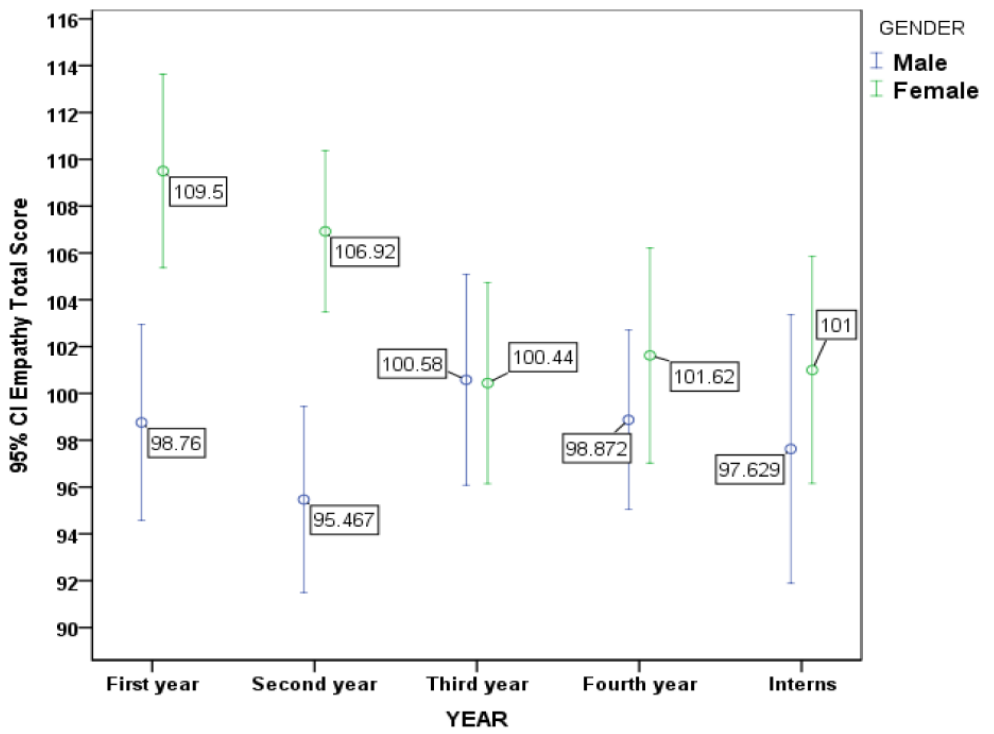

Footnotes for figure 1: $X$ - axis shows year of medical student; $Y$-axis shows JSE (S-version) Empathy scores; Green and blue lines depict male and female students' mean of Empathy $\pm 95 \%$ Confidence Interval respectively.
Independent sample $t$ test is done for difference in mean values between male and female students of each year, Significance calculated as in First year: $p<0.01$, Second: $p<0.01$, Third: $p=0.96$, Fourth: $p=0.36$ and Interns: $p=0.38$. 
Table3: Year-wise difference in empathy in male and female medical students.

\begin{tabular}{|c|c|c|c|c|c|c|c|}
\hline \multirow[t]{2}{*}{ GENDER } & & \multirow[t]{2}{*}{$\mathrm{N}$} & \multirow[t]{2}{*}{ Mean } & \multirow[t]{2}{*}{ Std. Deviation } & \multicolumn{2}{|c|}{$\begin{array}{l}95 \% \text { Confidence } \\
\text { Interval for Mean }\end{array}$} & \multirow{2}{*}{$\begin{array}{c}\text { Significance } \\
\text { ANOVA }\end{array}$} \\
\hline & & & & & Lower Limit & Upper Limit & \\
\hline \multirow{6}{*}{ Male } & First year & 50 & 98.76 & 14.698 & 94.58 & 102.94 & \multirow{6}{*}{$\begin{array}{l}F(4,222)= \\
0.76, \\
p=0.54\end{array}$} \\
\hline & Second year & 45 & 95.47 & 13.264 & 91.48 & 99.45 & \\
\hline & Third year & 50 & 100.58 & 15.835 & 96.08 & 105.08 & \\
\hline & Fourth year & 47 & 98.87 & 13.036 & 95.04 & 102.70 & \\
\hline & Interns & 35 & 97.63 & 16.710 & 91.89 & 103.37 & \\
\hline & Total & 227 & 98.36 & 14.662 & 96.44 & 100.27 & \\
\hline \multirow{6}{*}{ Female } & First year & 50 & 109.50 & 14.541 & 105.37 & 113.63 & \multirow{6}{*}{$\begin{array}{l}F(4,238)=3.7 \\
p=0.006\end{array}$} \\
\hline & Second year & 63 & 106.92 & 13.688 & 103.47 & 110.37 & \\
\hline & Third year & 50 & 100.44 & 15.105 & 96.15 & 104.73 & \\
\hline & Fourth year & 53 & 101.62 & 16.668 & 97.03 & 106.22 & \\
\hline & Interns & 27 & 101.00 & 12.251 & 96.15 & 105.85 & \\
\hline & Total & 243 & 104.30 & 15.036 & 102.40 & 106.20 & \\
\hline
\end{tabular}

Post Hoc test: Bonferroni: Mean difference between first and third year female students' Empathy=9.06, $p=0.023$. Among Other years, $p>0.05$.

\section{Discussion:}

In the present study, inferences noted were :

1. Female medical students have significantly higher empathy than male medical students.

2. Empathy levels declined from first year students to second year students, but from 3rd year it remains almost constant till internship.

3.Choosing of specialities did not had an impact on empathy level scores.

All the medical students present on the day of the study had given consent and participated in our study (Table 1). This is in contrast to the poor response rate of third-year students $(77.2 \%)$ in the study by Chen et. al, in which a steady decrease in empathy scores was found. ${ }^{[8]}$

Chen et al ${ }^{[12]}$ reported higher mean empathy scores (114.3) compared to other studies like Kataoka et al. (104.30) ${ }^{[13]}$, Rahimi et al. (104.1) ${ }^{[16]}$ and Shashi Kumar et al. (102.91) [24] and in current study it was 101.41.

There is a need to further explore why most Asian students have almost similar scores but lower than the American studies. $^{[11,12]}$

The curriculum in India is different in many respects from medical schools in the US, Japan and Iran. The students are exposed to clinical rotation from second year onwards (third semester), vast syllabus, practical live case based scenarios than virtual scenarios, recent horizontal and vertical integration of clinical and non clinical subjects etc., recently the medical board is taking steps to change from syllabus based curriculum to competency based curriculum.
But there is a decline of score in second year but is statistically not significant (Tables 2). Interestingly there is an increase in empathy scores in the beginning of third year this could be explained by the fact that these students were trained in patient history taking and communicating with the patient in the preceding year, whom were actively seeing patients and were also engaged in the clinical rotation.

Kataoka et al in their study highlighted the point that different entrance methods in medical schools and different cultures across various countries may account for variation in empathy. (9). The curriculum in our college differs from western and Japanese colleges in firstly students here have no exposure to humanities subjects such as economy, literature, philosophy and other sciences as found in Japanese medical curriculum and undergraduate curriculum in USA. Secondly students in this college are exposed to clinical rotation right from the beginning of second year in contrast to beginning of third year in USA, and in Japan. ${ }^{(8,9)}$ Also, an interview to seek out the motivations of a student is not an integral part of the recruitment process into medical school in India as it is in the USA.

Another factor influencing empathy could be that students in clinical rotation are less likely to relate to the patient and regard him as a person rather than a "case" meant for study. Probable reason could be lack of constant follow up the patients for a longer period.

In a systematic review of study with medical students, Neumann et al. ${ }^{[25]}$ had put forth some important issues that might explain the decline in empathy throughout their training. 
One of them was that students themselves were probably overwhelmed by the mortality and morbidity that they encounter in clinical rotation and most often they do not have anybody to help them to deal with such issues. This is also a valid concern in India, where students generally do not have a facility (such as a student counsellor) available in their college to express their feelings in relation to these phenomena. Recruiting a student counsellor on a full time basis in medical colleges will address day to day stress issues of students.

A significant factor found in another Indian study was distress in the form of reduced quality of life, depression, burnout, suicidal attempts and increased substance abuse arising from a variety of factors such as declining idealism, loss of enthusiasm since joining medical college, lack of knowledge in handling stress related issues and reduced contact with family. ${ }^{[24]}$ The latter could be one cause of decline of empathy among our medical students as most of them stay in hostels away from home and have only 6 to 8 weeks of vacation during an academic year to be with their families. The present study does not measure any distress, quality of life or other variables. It can be taken by future researchers to improve medical education.

In this study there is significant difference $(p=0.001)$ in empathy scores between male and female with the latter scoring more than male students (mean female students $=104.3$ vs. male students $=98.4$, Standard deviation $=15.1 \& 14.7$ respectively) (Table 1), which is in consonance with studies from USA, Portugal and Japan, Iran, Brazil.[12, 13, 15, 26, 27] Female students by nature are more caring and loving and probably less affected by factors that tend to diminish empathy. It was interesting to note that more female students tend to choose people-oriented specialties but due to their smaller numbers, no significant statistical difference could be arrived at (Table2).

In our study, no significant difference in empathy scores was noted among those choosing different groups of specialities $(p=0.2468)$. Whereas Chen et al. [12] Mariana et al. [27] had found students preferring people-oriented specialities to have more empathy than those preferring technology-oriented specialities.

In the present study, there was no statistically significant difference between empathy among choices of speciality groups across the year of education ( $p>0.05$ ). On the contrary, Hojat et. al found a decline in empathy scores among those choosing a technology-oriented specialization in third year.[7] Chen et. al have also reported increased empathy among those choosing people-oriented specialization and the difference is statistically significant $(p=0.002)$.[11] They also found little difference in mean empathy scores across first to third year among those choosing other specialities. However, in our study the variance in empathy score across various years is not significant.

\section{Limitations:}

1) Fewer number of respondents who were doing their internship.

2) Being a cross-sectional study, the variance seen at different years of training may not be representative of actual decline from high baseline scores.

\section{Conclusion}

Current study concludes that female students are more empathetic than male students. In the recent years, we can see an increasing number of female students entering into medical education. There might be a difference in the type of medical care rendered to the patient and this area has a scope for further studies.

The medical curriculum should be set up in such a way that the students are educated in communication skills. This could help them to empathise with patients in better and more effective ways. The students should be taught not only to treat the physical aspect of the disease but also care about the emotional wellbeing of the patient. This helps in developing a positive patient-doctor relationship.

The present curriculum and clinical training hardly contains anything that helps our students to deal with the effect of the mortality and morbidity that students encounter in clinical rotation. In campus full time student counsellor should be available to all students for the healthy, timely ventilation of stress related issues.

Education in ethics and behavioural sciences may be effective in increasing the empathy levels among the medical students. This would lead to personal growth, career satisfaction, and optimal clinical outcomes.

A longitudinal follow up study including a larger sample from a greater number of colleges would help to find out if a decline in empathy with progressing years in medical college truly exists. It would also help understand the effect of gender and variation in choice of speciality based on empathy score. Also, it could further ascertain what factors could be instrumental in the decline of empathy through progressive medical training.

\section{Bibliography:}

1. Barrett-Lennard GT. The empathy cycle: Refinement of a nuclear concept. Journal of Counseling Psychology. 1981 Mar;28(2):91.

2. Feighny KM, Monaco M, Arnold L. Empathy training to improve physician-patient communication skills. Academic Medicine. 1995 May 1;70(5):435-6.

3. Biswas B, Haldar A, Dasgupta A, Mallick N, Karmakar A. An epidemiological study on empathy and its correlates: A cross-sectional assessment among medical students of a government medical college of India. Indian journal of psychological medicine. $2018 \mathrm{Jul} ; 40(4): 364$. 
4. Mercer SW, Reynolds WJ. Empathy and quality of care. $\mathrm{Br}$ J Gen Pract. 2002 Oct 1;52(Suppl):S9-12.

5. Osler W. Aequanimitas: With Other Addresses to Medical Students, Nurses and Pratitioners of Medicine. P. Blakiston; 1922.

6. Quince T, Thiemann P, Benson J, Hyde S. Undergraduate medical students' empathy: current perspectives. Advances in medical education and practice. 2016;7:443.

7. Hojat M, Gonnella JS, Mangione S, Nasca TJ, Veloski JJ, Erdmann JB, Callahan CA, Magee M. Empathy in medical students as related to academic performance, clinical competence and gender. Medical education. 2002 Jun;36(6):522-7.

8. Rabin PL, Rabin D. The Care of the Patient: Francis Peabody Revisited: Landmark Perspective. JAMA: The Journal of the American Medical Association. 1984 Aug 10;252(6):819-20.

9. Pohontsch NJ, Stark A, Ehrhardt M, Kötter T, Scherer M. Influences on students' empathy in medical education: an exploratory interview study with medical students in their third and last year. BMC medical education. 2018 Dec;18(1):1-9.

10. Newton BW, Barber L, Clardy J, Cleveland E, O'Sullivan P. Is there hardening of the heart during medical school?. Academic Medicine. 2008 Mar 1;83(3):244-9.

11. Chen DC, Pahilan ME, Orlander JD. Comparing a selfadministered measure of empathy with observed behavior among medical students. Journal of general internal medicine. 2010 Mar 1;25(3):200-2.

12. Chen D, Lew R, Hershman W, Orlander J. A cross-sectional measurement of medical student empathy. Journal of general internal medicine. 2007 Oct 1;22(10):1434-8.

13. Kataoka HU, Koide N, Ochi K, Hojat M, Gonnella JS. Measurement of empathy among Japanese medical students: psychometrics and score differences by gender and level of medical education. Academic medicine. 2009 Sep 1;84(9):1192-7.

14. Roh MS, Hahm BJ, Lee DH, Suh DH. Evaluation of empathy among Korean medical students: a cross-sectional study using the Korean Version of the Jefferson Scale of Physician Empathy. Teaching and learning in medicine. 2010 Jun 22;22(3):167-71.

15. Hojat M, Mangione S, Nasca TJ, Rattner S, Erdmann JB, Gonnella JS, Magee M. An empirical study of decline in empathy in medical school. Medical education. 2004 Sep;38(9):934-41.

16. Rahimi-Madiseh M, Tavakol M, Dennick R, Nasiri J. Empathy in Iranian medical students: a preliminary psychometric analysis and differences by gender and year of medical school. Medical teacher. 2010 Nov 1;32(11):e471-8.
17. Nunes P, Williams S, Sa B, Stevenson K. A study of empathy decline in students from five health disciplines during their first year of training. Int J Med Educ. 2011 Aug 2;2:12-7.

18. Tavakol S, Dennick R, Tavakol M. Psychometric properties and confirmatory factor analysis of the Jefferson Scale of Physician Empathy. BMC medical education. 2011 Dec 1;11(1):54.

19. Rueckert L, Naybar N. Gender differences in empathy: The role of the right hemisphere. Brain and cognition. 2008 Jul 1;67(2):162-7.

20. Gazzola V, Aziz-Zadeh L, Keysers C. Empathy and the somatotopic auditory mirror system in humans. Current biology. 2006 Sep 19;16(18):1824-9.

21. Shamay-Tsoory SG, Aharon-Peretz J, Perry D. Two systems for empathy: a double dissociation between emotional and cognitive empathy in inferior frontal gyrus versus ventromedial prefrontal lesions. Brain. 2009 Mar 1;132(3):617-27.

22. Magalhães $E$, Salgueira AP, Costa $P$, Costa MJ. Empathy in senior year and first year medical students: a crosssectional study. BMC Medical education. 2011 Dec $1 ; 11(1): 52$.

23. Hojat M, Maxwell K, Carroll S, Cass J. Jefferson Scale of Empathy (JSE) User Guide. Philadelphia, Pennsylvania, USA; 2016.

24. Shashikumar R, Chaudhary R, Ryali VS, Bhat PS, Srivastava K, Prakash J, Basannar D. Cross sectional assessment of empathy among undergraduates from a medical college. medical journal armed forces india. 2014 Apr 1;70(2):17985.

25. Neumann M, Edelhäuser F, Tauschel D, Fischer MR, Wirtz M, Woopen C, Haramati A, Scheffer C. Empathy decline and its reasons: a systematic review of studies with medical students and residents. Academic medicine. 2011 Aug 1;86(8):996-1009.

26. Khademalhosseini M, Khademalhosseini Z, Mahmoodian F. Comparison of empathy score among medical students in both basic and clinical levels. Journal of Advances in Medical Education \& Professionalism. 2014 Apr;2(2):88.

27. Santos MA, Grosseman S, Morelli TC, Giuliano IC, Erdmann TR. Empathy differences by gender and specialty preference in medical students: a study in Brazil. International journal of medical education. 2016;7:149.

How to cite this article : Shiv Kumar R, Puli SK, Kishan P, Sanjay ND, Sphurthi P, Sultana A, Kashif Momin. A cross-sectional study of factors determining empathy levels among undergraduate medical students of a medical college in Northern Telangana. Perspectives in Medical Research 2020; 8 (3):49-55

DOI: $10.47799 /$ pimr.0803.11

Sources of Support: Nil, Conflict of interest: None declared 